\title{
The use of surface area and of body-weight as standards of reference in studies on human energy expenditure
}

\author{
By J. V. G. A. DURNIN \\ Institute of Physiology, University of Glasgow \\ (Received 10 Fuly 1958)
}

In assessing the nutritional status of populations, it is becoming increasingly common to measure not only the total food intake but also the energy expenditure of groups of individuals. It is often difficult to compare the results obtained by different authors in such studies of energy expenditure because of the diverse ways in which these results may be expressed. The metabolic cost of a period of work, or of any particular activity, may be given as gross $\mathrm{Cal}$. or net $\mathrm{Cal}$.; net Cal. may involve a deduction for basal metabolism (B.M.R.) or for specific dynamic action (S.D.A.) or for both. These results may then appear as $\mathrm{Cal}$./h or $\mathrm{Cal}$./min; they may be expressed as $\mathrm{Cal} . / \mathrm{m}^{2}$ body surface area or as Cal./kg body-weight; they may be Cal. per gross body-weight or per fat-free body-weight. For example, Carpenter \& Benedict (1909) express their results as gross Cal./h. Cathcart \& Orr (Igrg) express theirs as gross Cal./h and gross Cal. $/ \mathrm{m}^{2} / \mathrm{h}$. Orr \& Leitch (1937-8) list the energy expenditure of general activities (e.g. knitting, washing, shoemaking, mining) as Cal./h after deduction of the expenditure in basal metabolism and after subtraction of $10 \%$ of the energy expenditure as due to S.D.A. Granati \& Busca (194I) give energy expenditure for a specific activity as Cal./ro min work with a deduction for the metabolism of rest. Marro, Milani \& Vigliani (1954) use gross Cal. $/ \mathrm{m}^{2} / \mathrm{h}$. Lehmann, Müller $\&$ Spitzer (1950) use net Cal. with a deduction for B.M.R. Christensen \& Högberg (I950) and Christensen (1953) quote results as gross Cal./min. Insull (1954) uses gross Cal./min. Buskirk, Kreider, Brebbia, Morana, Daniels, Welch, Mann, Insull \& Friedemann (I956) express results as Cal./kg bodyweight $/ \mathrm{h}$ and as Cal. $/ \mathrm{m}^{2} / \mathrm{h}$. Welch, Marcinek, Buskirk \& Iampietro (I957) give results as net Cal./min with deductions for B.M.R. and S.D.A. Therefore, before data from different sources can be compared much recalculation must be done. Passmore $\&$ Durnin (I955) had this difficulty when they drew up tables to express energy expenditure in different activities in a consistent manner. There would often appear to be little reason for this diversity. The present paper discusses this problem with especial regard to the use of surface area and of body-weight as the particular standard of reference.

\section{METHODS}

Individual measurements of the energy expenditure of about I 60 adult subjects, male and female, with a range in age from 18 to 67 years, and in weight from 42 to $90 \mathrm{~kg}$, were used to compare gross body-weight and surface area as standards of reference. Some of the results used were taken from those given by Durnin \& Namyslowski (1958); the methods used in obtaining these results are described fully in that paper. 
Others are from the following: Garry, Passmore, Warnock \& Durnin (1955); Durnin \& Mikulicic (1955); Durnin, Blake \& Brockway (1957) and some are from unpublished results obtained in this laboratory. Scatter diagrams were made with results of energy expenditure in some general activities as the ordinate and surface area or body-weight as the abscissa. The activities included sitting, standing, walking on the level, walking on an incline, and also two arm exercises. Here then is a range of activities where the body-weight both would and would not be expected to influence the results.

Multiple regression analyses were done on these results, with gross body-weight in $\mathrm{kg}$, surface area in $\mathrm{m}^{2}$ (calculated from the Du Bois formula), and energy expenditure in Cal./min as the three variables.

\section{RESULTS AND DISCUSSION}

The results of the multiple regression analysis for each separate set of values (that is the values for sitting, for standing, for the two exercises on an arm ergometer, and for walking on the level and on an incline on the treadmill) were all of a uniform pattern. The simple correlation coefficients show a high correlation between gross body-weight and surface area, and no significant difference between the correlation coefficient for energy expenditure and body-weight and that for energy expenditure and surface area. The separate simple correlation coefficients were as shown in Table $\mathbf{r}$.

Table I. Correlation coefficients

\begin{tabular}{|c|c|}
\hline Correlation between & Coefficient, $r$ \\
\hline \multicolumn{2}{|l|}{ Sitting } \\
\hline $\begin{array}{l}\text { Body-weight and surface area } \\
\text { Energy expenditure and body-weight } \\
\text { Energy expenditure and surface area }\end{array}$ & $\begin{array}{l}0.88 \\
0.66 \\
0.60\end{array}$ \\
\hline \multicolumn{2}{|l|}{ Standing } \\
\hline $\begin{array}{l}\text { Body-weight and surface area } \\
\text { Energy expenditure and body-weight } \\
\text { Energy expenditure and surface area }\end{array}$ & $\begin{array}{l}0.92 \\
0.60 \\
0.61\end{array}$ \\
\hline \multicolumn{2}{|l|}{ Arm exercise, I } \\
\hline $\begin{array}{l}\text { Body-weight and surface area } \\
\text { Energy expenditure and body-weight } \\
\text { Energy expenditure and surface area }\end{array}$ & $\begin{array}{l}0.88 \\
0.33 \\
0.33\end{array}$ \\
\hline \multicolumn{2}{|l|}{ Arm exercise, 2} \\
\hline $\begin{array}{l}\text { Body-weight and surface area } \\
\text { Energy expenditure and body-weight } \\
\text { Energy expenditure and surface area }\end{array}$ & $\begin{array}{l}0.88 \\
0.34 \\
0.34\end{array}$ \\
\hline \multicolumn{2}{|l|}{ Walking } \\
\hline $\begin{array}{l}\text { Body-weight and surface area } \\
\text { Energy expenditure and body-weight } \\
\text { Energy expenditure and surface area } \\
\text { Climbing }\end{array}$ & $\begin{array}{l}0.95 \\
0.68 \\
0.60\end{array}$ \\
\hline $\begin{array}{l}\text { Body-weight and surface area } \\
\text { Energy expenditure and body-weight } \\
\text { Energy expenditure and surface area }\end{array}$ & $\begin{array}{l}0.96 \\
0.77 \\
0.78\end{array}$ \\
\hline
\end{tabular}

(The small differences in the correlation coefficients between body-weight and surface area are due to the fact that the groups of subjects differed somewhat for the separate activities.) 
The multiple regression analysis of energy expenditure on body-weight and surface area showed quite clearly that there was no purpose in using surface area, rather than body-weight, as a standard of reference. Both are apparently equally useful, but weight is easily and accurately measured whereas surface area is not a measured unit but a calculated one; the error involved in the calculation may sometimes be considerable for any one individual.

Where there is no movement of the body as a whole, it might be expected that surface area would be of most importance in regulating the energy expended. Yet obviously it has no greater import than body-weight. This problem has been discussed by other writers in some detail. For example, Kleiber (1956) has dealt very interestingly and at some length with the philosophical, psychological and some of the physiological implications. In his review, he also mentions recent work on the use of the fat-free body mass as a standard of reference. At present, for many reasons, this measurement is of dubious value in the great majority of metabolic studies. The methods for determining fat-free body-weight are of unknown accuracy; they are very obviously by no means generally applicable, especially in field work. Moreover body fat, within the limits commonly met with in physiological research, cannot be ignored when one is concerned with measurements of energy expenditure. It is highly unlikely that the use, as a standard of reference, of fat-free body-weight rather than of gross bodyweight will be an appreciable improvement. It should also be repeated here that, in this context, the use of any unit of reference, whether it be 'per $\mathrm{m}^{2}$ ' or 'per $\mathrm{kg}$ ', implies a fundamental biological error on the part of the perpetrator. Such use infers that the (straight) regression line passes through the origin; a straight regression line may fit the data adequately but if this line does not pass through the origin (which generally it will not do) the use of a ratio correction is not justified.

If young children are excluded and only adolescents and adults considered, it seems probable then that gross body-weight is as suitable a standard as is known at present for dealing with measurements of energy expenditure. The only important exception to this general statement is in comparative physiology, where possibly surface area may be a more useful index.

With regard to the unit of time, as has been mentioned by Passmore \& Durnin (1955), values expressed as Cal./h may be misinterpreted; very few activities, apart from sleep, are carried out at a steady rate over such a long period. It is much more common for both work and leisure to occur in periods of varying intensity lasting for some minutes only. It would therefore appear to be much more logical to express results as $\mathrm{Cal} . / \mathrm{min}$.

The use of net values instead of gross is somewhat more complex, and it has been common in the past to give energy expenditure in net Cal. with a deduction, usually for B.M.R. Very seldom is the B.M.R. actually measured-it is derived from tables. Again, the error here may sometimes be considerable, and it appears rather illogical to make a deduction which, for any activity involving exercise, will be very small and of unknown accuracy.

In conclusion, it would be most useful to have results obtained by indirect calorimetry expressed in a consistent manner, which would certainly aid easy comparison 
between the results of different workers. There appears to be no good reason why the standard unit of reference should not be gross Cal./min, as long as the weight of the subject is stated; physical characteristics of subjects in any experiment should, in any event, always be given.

\section{SUMMARY}

I. It would be helpful if the results of measurements of energy expenditure of man were expressed in a uniform manner.

2. Results for about 160 subjects were graphed and submitted to a multiple regression analysis; the results showed that surface area is no more useful as a standard of reference than gross body-weight.

3. Arguments are put forward in favour of giving results of energy expenditure as Cal./min/gross body-weight.

I am grateful to Dr R. A. Robb of the Statistics Department, University of Glasgow, for advice and help with the statistical analysis.

This research programme has been supported by a grant from the Scottish Hospital Endowments Research Trust.

\section{REFERENCES}

Buskirk, E. R., Kreider, M., Brebbia, R., Morana, N., Daniels, F., Welch, B. E., Mann, J. B., Insull, W. \& Friedemann, T. E. (1956). U.S. Army. Quartermaster Research and Development Center. Environmental Protection Division. Tech. Rep. EP-33.

Carpenter, T. M. \& Benedict, F. G. (1909). F. biol. Chem. 6, 27 I.

Cathcart, E. P. \& Orr, J. B. (I919). Energy Expenditure of the Infantry Recruit in Training. London: H.M. Stationery Office.

Christensen, E. H. (1953). In Ergonomics Society, Symposium on Fatigue, p. 93. [W. F. Floyd and A. T. Welford, editors.] London: H. K. Lewis and Co. Ltd.

Christensen, E. H. \& Högberg, P. (1950). Arbeitsphysiologie, 14, 292.

Durnin, J. V. G. A., Blake, E. C. \& Brockway, J. M. (1957). Brit. F. Nutr. II, 85.

Durnin, J. V. G. A. \& Mikulicic, V. (1955). Quart. F. exp. Physiol. 41, 442.

Durnin, J. V. G. A. \& Namyslowski, L. (1958). F. Physiol. 143, 573.

Garry, R. C., Passmore, R., Warnock, G. M. \& Durnin, J. V. G. A. (1955). Spec. Rep. Ser. med. Res. Coun., Lond., no. 289.

Granati, A. \& Busca, L. (194I). Quad. Nutr. 8, 1.

Insull, W. Jr. (1954). U.S. Army. Med. Nutr. Lab. Rep. no. 146.

Kleiber, M. (1956). Ann. Rev. Physiol. r8, 35.

Lehmann, G., Müller, E. A. \& Spitzer, H. (1950). Arbeitsphysiologie, 14, 166.

Marro, F., Milani, V. \& Vigliani, E. C. (1954). Med. d. Lavoro, 45, I2.

Orr, J. B. \& Leitch, I. (1937-8). Nutr. Abstr. Rev. 7, 509.

Passmore, R. \& Durnin, J. V. G. A. (1955). Physiol. Rev. 35, 8 ог.

Welch, B. E., Marcinek, J. G., Buskirk, E. R. \& Iampietro, P. F. (1957). U.S. Army. Med. Nutr. Lab. Rep. no. 196. 